\title{
Bias-Enhanced Formation of Metastable and Multiphase Boron Nitride Coating in Microwave Plasma Chemical Vapor Deposition
}

\author{
Kallol Chakrabarty (D), Paul A. Baker (D), Vineeth M. Vijayan (D) and Shane A. Catledge *(D) \\ Department of Physics, University of Alabama at Birmingham, Birmingham, AL 35294, USA; \\ kallo189@uab.edu (K.C.); pabaker@uab.edu (P.A.B.); vineeth@uab.edu (V.M.V.) \\ * Correspondence: catledge@uab.edu
}

Citation: Chakrabarty, K.; Baker, P.A.; Vijayan, V.M.; Catledge, S.A. Bias-Enhanced Formation of Metastable and Multiphase Boron Nitride Coating in Microwave Plasma Chemical Vapor Deposition. Materials 2021, 14, 7167. https://doi.org/ $10.3390 /$ ma14237167

Academic Editor: Andrzej Dziedzic

Received: 28 September 2021 Accepted: 15 November 2021 Published: 25 November 2021

Publisher's Note: MDPI stays neutral with regard to jurisdictional claims in published maps and institutional affiliations.

Copyright: (c) 2021 by the authors. Licensee MDPI, Basel, Switzerland. This article is an open access article distributed under the terms and conditions of the Creative Commons Attribution (CC BY) license (https:// creativecommons.org/licenses/by/ $4.0 /)$.
Abstract: Boron nitride (BN) is primarily a synthetically produced advanced ceramic material. It is isoelectronic to carbon and, like carbon, can exist as several polymorphic modifications. Microwave plasma chemical vapor deposition (MPCVD) of metastable wurtzite boron nitride is reported for the first time and found to be facilitated by the application of direct current (DC) bias to the substrate. The applied negative DC bias was found to yield a higher content of $s p^{3}$ bonded BN in both cubic and metastable wurtzite structural forms. This is confirmed by X-ray photoelectron spectroscopy (XPS) and Fourier transform infrared spectroscopy (FTIR). Nano-indentation measurements reveal an average coating hardness of $25 \mathrm{GPa}$ with some measurements as high as $31 \mathrm{GPa}$, consistent with a substantial fraction of $s p^{3}$ bonding mixed with the hexagonal $s p^{2}$ bonded BN phase.

Keywords: ceramics/coating materials; chemical synthesis; vapor deposition; mechanical properties

\section{Introduction}

Boron nitride $(\mathrm{BN})$ is a covalently bonded ceramic material and a member of the Group III nitrides. It exhibits many outstanding properties, such as chemical inertness, thermal conductivity, very good mechanical properties, and electrical insulating properties [1-3]. Boron nitride (BN) exists in multiple forms, including amorphous BN $(a$-BN), hexagonal $\mathrm{BN}(h-\mathrm{BN})$, rhombohedral BN $(r-\mathrm{BN})$, cubic BN $(c-\mathrm{BN})$, and wurtzite $\mathrm{BN}(w-\mathrm{BN})$. While $r$-BN is basically $h$-BN with a slight variation in the stacking of individual layers, $w$ - $\mathrm{BN}$ is distorted $c$-BN. Both $r$-BN and $h$-BN have $s p^{2}$ hybridization, while $c$-BN and $w$-BN have $s p^{3}$ hybridization in their covalent bond, thus giving rise to widely varying properties of the material. The hardness of cubic boron nitride is second only to diamond, but $c$-BN has better oxidation resistance at high temperatures. Wurtzite boron nitride has a hardness which even exceeds diamond and can usually only be produced via shock compression methods, such as detonation, or static compression at high pressures [4]. The oxidization temperature of the $c-\mathrm{BN}$ and $\mathrm{w}-\mathrm{BN}$ is also about twice the temperature of diamond in ambient environments and, unlike diamond, $c$-BN does not react with molten ferrous materials [5-9]. Among all the predominantly covalently bonded materials, $c-B N$ and $w$-BN also have the widest band gap $(6.2 \pm 0.2 \mathrm{eV})$ and can be doped for both p-type and n-type conductivity [5-13]. Another interesting property of $c-\mathrm{BN}$ is its transparency to a broad range of electromagnetic radiation from the ultraviolet to the infrared [14]. The above-mentioned outstanding properties of $c$-BN and $w$-BN make it a very promising candidate for hard coatings in grinding and cutting tools, electronic and optoelectronic device applications such as deep-ultraviolet detectors, light-emitting diodes, high-power/high-speed transistors for operation at high temperatures in harsh environments, and UV-Vis-IR transparent optical devices such as lenses and windows [3,14-16]. It has recently been reported that $c$-BN can be biocompatible and non-cytotoxic, and can be used as a novel scaffold for biomedical applications [15].

Boron nitride is not found naturally; it has to be produced from boron and nitrogen precursors. Different methods and experimental conditions have been used to synthesize 
BN from a variety of boron and nitrogen precursors [17-24]. Preparation of boron nitride (BN) was reported from high pressure/high temperature synthesis using diamond anvil cell/laser heating. However, high pressure/high temperature synthesis can be expensive and often only generates very little amounts of material. In contrast, chemical vapor deposition (CVD) has proven to be a scalable technology for synthesizing a wide range of coating materials including BN coatings with large area uniformity and at the same time it is also very cost effective [17-20,24,25]. Laser chemical vapor deposition was also used to high yield synthesis of cubic and hexagonal boron nitride [26]. At ordinary temperatures and pressures $h-\mathrm{BN}$ is the stable structure of $\mathrm{BN}$ and $c-\mathrm{BN}$ at high temperatures and pressures. The wurtzite phase of $\mathrm{BN}$ is metastable at all pressures and temperatures and its stabilization is challenging because of the very low kinetic barrier for the transformation back to ambient phases $[4,23]$. Among the different allotropes of boron nitride, $c$-BN and $w$-BN are superhard in nature [27]. The $h$-BN phase is the most stable and therefore more easily formed under a wider range of conditions compared to the $c$ - $\mathrm{BN}$ and $\mathrm{w}$ BN phases [28]. c-BN has been deposited both by the low-pressure CVD method and by the high-pressure-high temperature process. Synthesis of the metastable wurtzite BN polymorph has only been reported by high-pressure-high temperature and shock compression methods $[4,27,29-31]$. Ion bombardment has been reported to be necessary in order to obtain $c$-BN coatings grown by CVD [32]. The objective of this research is to investigate deposition conditions using substrate bias leading to $\mathrm{BN}$ coatings containing a significant fraction of $s p^{3}$ bonds. This is expected to yield much higher hardness than that offered by $h$-BN. In this work, we report the first evidence of metastable $w$-BN grown in a low-pressure plasma environment, facilitated by application of substrate bias. The $w$-BN is shown to form alongside $c$ - $\mathrm{BN}$ and $h$-BN in this process.

\section{Materials and Methods}

\subsection{MPCVD Process}

Boron nitride coatings were grown in a microwave plasma chemical vapor deposition (MPCVD) system-details provided elsewhere [33,34]. Inside the MPCVD chamber, the substrate was heated by direct contact with the plasma. Water was used to cool both the sample stage and the outer resonance cavity jacket. From the resonance cavity a lowpressure plasma environment was isolated by a quartz bell jar. N-type (100)-oriented silicon substrates with $525 \mu \mathrm{m}$ thickness were placed on the surface of a $0.5^{\prime \prime}$ diameter molybdenum screw located along the central axis of the bell jar. The substrate was cleaned in acetone, methanol, and then distilled water. Microwave power of $1 \mathrm{~kW}$ and chamber pressure of 15 Torr were used in the growth process. The carrier gas was hydrogen $\left(\mathrm{H}_{2}\right)$ and in this study the reactive gas was a diborane mixture $\left(95 \% \mathrm{H}_{2}, 5 \% \mathrm{~B}_{2} \mathrm{H}_{6}\right)$ and $\mathrm{N}_{2}$. The gas flow rates were: 500 standard cubic centimeters per minute (SCCM) of hydrogen, 9 SCCM of the diborane mixture, and 0.4 SCCM of $\mathrm{N}_{2}$. Two types of samples were grown with the same experimental conditions at an average substrate temperature of $800{ }^{\circ} \mathrm{C}$ with the only variation being that one sample was synthesized without the presence of bias and the other was synthesized with the applied substrate bias. A Sorensen DCS 600-1.7E power supply (AMETEK Programmable Power, Inc. San Diego, CA, USA) provided the bias voltage to negatively charge the substrate while maintaining the chamber wall of the MPCVD grounded. The corresponding electric field that is created accelerates positively charged ions towards the substrate. Negative $400 \mathrm{~V}$ was used in the experiment resulting in an initial sample current of $20 \mathrm{~mA}$. Maximum current was found using $-400 \mathrm{~V}$ so in this study it was used as external voltage. The current decreased gradually to zero during the initial $15 \mathrm{~min}$ of deposition. This is believed to be due to the insulating nature of boron nitride that gradually forms on the silicon substrates. The external power supply was turned off after the current reached zero. 


\subsection{Characterization Techniques}

Samples were examined using Fourier transform infrared spectroscopy (FTIR), X-ray photoelectron spectroscopy (XPS), glancing-angle X-ray diffraction (XRD), nano-indentation, and scanning electron microscopy (SEM). To learn the chemical properties of the coatings, the Bruker alpha FTIR spectrometer (Bruker Corporation, Billerica, MA, USA) was used (ranging from 1800 to $600 \mathrm{~cm}^{-1}$ ). The FTIR spectra were recorded using a total number of 1024 scans with a $4 \mathrm{~cm}^{-1}$ resolution. To determine the elemental compositions and chemical bonding of the boron nitride coating, XPS was carried out with a Phi Electronics Versaprobe 5000 (Phi Electronics, Chanhassen, MN, USA), equipped with a micro-focused Al monochromatic source $(\lambda=1486.6 \mathrm{eV})$. A Panalytical Empyrean X-ray diffractometer (Malvern, Panalytical, Almelo, Nederland) (Copper $K_{\alpha 1}, \lambda=1.54059 \AA$ ) was used to obtain the XRD pattern. A glancing-angle 2-theta scan with an angle of incidence of 1 degree was carried out to attain the XRD patterns. A hybrid monochromator (Malvern, Panalytical, Almelo, Nederland) with a $1 / 8^{\circ}$ divergence slit and a $1 / 16^{\circ}$ anti-scattering slit, as well as a parallel plate collimator (Malvern, Panalytical, Almelo, Nederland) on the diffracted beam path with a proportional detector (Malvern, Panalytical, Almelo, Nederland) were used in the XRD instrumentation. The nano-indentation hardness was measured using an Agilent Nano Indenter G200 (MTS Nano Instruments, Oak Ridge, TN, USA) with a Berkovich diamond tip with nominal radius of $50 \mathrm{~nm}$. Before and after indenting our sample for calibration, a fused silica reference with an accepted Young's modulus value of $72 \mathrm{GPa}$ was evaluated. We can establish that the tip shape did not change during the examination of the sample because the range of Young's modulus of this silica standard was consistent with the accepted value (before and after indenting our sample). All indents were created to a maximum depth of $600 \mathrm{~nm}$, including those on the silica. The measured hardness was determined at maximum load. The morphology of the bias-enhanced coating was studied using the SEM instrumentation of an FEI Quanta TM 650 FEG Scanning Electron Microscope (Thermo Fisher Scientific, Hillsboro, OR, USA) at a $5 \mathrm{kV}$ beam voltage.

\section{Results}

\subsection{Fourier Transform Infrared Spectroscopy (FTIR)}

FTIR spectral analysis was utilized to get information on the effect of biasing on the bonding environment of boron nitride. Figure 1 shows FTIR of the BN coatings grown (a) without applied bias and (b) with applied substrate bias. Both of the FTIR spectra exhibit several peaks in the fingerprint region $\left(1500-500 \mathrm{~cm}^{-1}\right)$. The BN coating deposited without a negative bias voltage shows two bands, at 1307 and $786 \mathrm{~cm}^{-1}$. These bands represent the in-plane (B-N) stretching mode and out-of-plane (B-N-B) bending modes of the $s p^{2}$ bonded hexagonal $(h-\mathrm{BN})$ phase, respectively $[35,36]$. These data show that the BN coating grown without applied bias consists primarily of the $s p^{2}$ bonded hexagonal $\mathrm{BN}$ phase. In contrast, the BN coating grown with applied bias shows two additional peaks at 1045 and $1224 \mathrm{~cm}^{-1}$, corresponding to the Restrahlen band of $c$-BN and the TO modes of $w$-BN, respectively $[35,37,38]$. These observations clearly suggest that applied biasing introduces $s p^{3}$ bonded cubic and wurtzite phases of BN. Taken together, the BN coating prepared without the applied bias consists of only the hexagonal phase whereas the BN coating prepared with the applied bias consists of a mixture of cubic, wurtzite and hexagonal phases. For the bias-enhanced BN coating, the wurtzite and cubic phases are more predominant compared to the hexagonal $\mathrm{BN}$ phase. The complete peak assignment is also given in Table 1. The volume fraction of the different $\mathrm{BN}$ phases of the bias-enhanced coating can be estimated by the relative intensities of the $w$-BN, $c-\mathrm{BN}$ and $h$-BN peaks using the following equation $[39,40]$.

$$
Q_{w-\mathrm{BN}}=\frac{I_{w-\mathrm{BN}}}{I_{c-\mathrm{BN}}+I_{w-\mathrm{BN}}+I_{h-\mathrm{BN}}}
$$



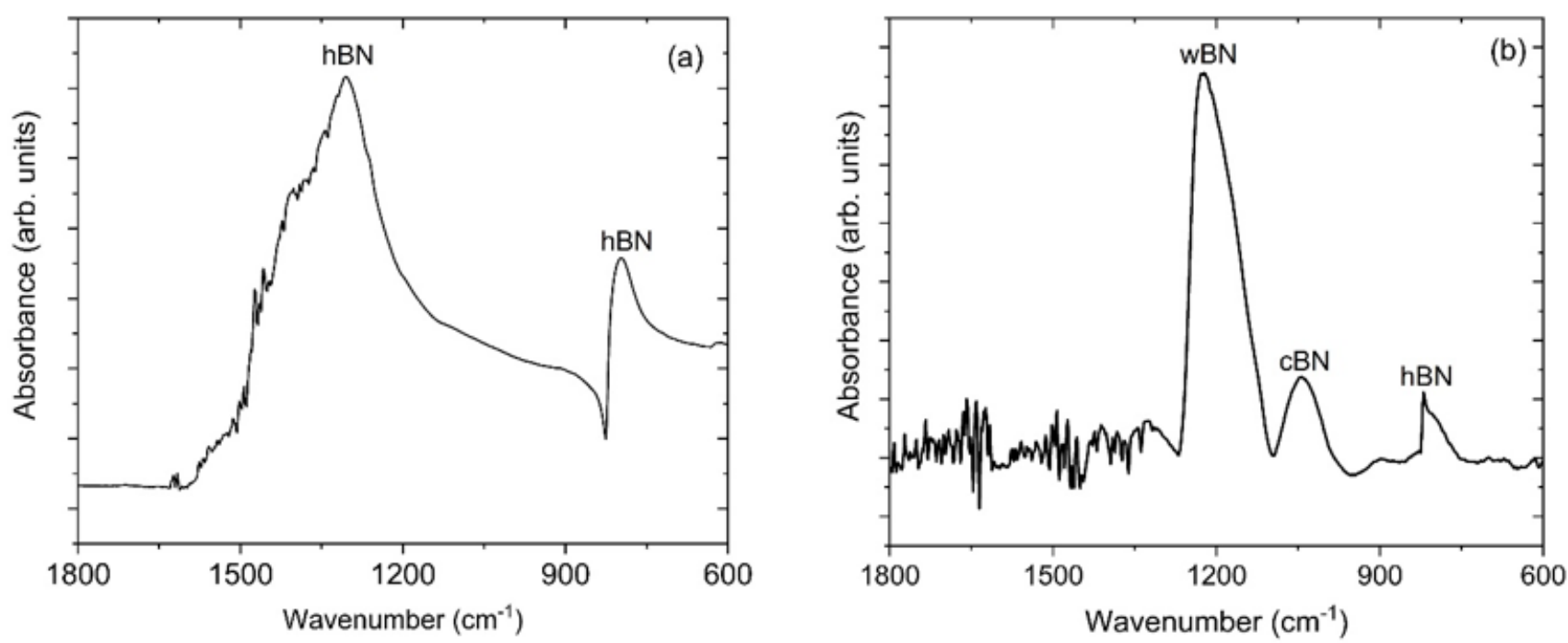

Figure 1. Fourier transform infrared spectroscopy (FTIR) of boron nitride coating (a) without applied bias and (b) with applied substrate bias. The coating grown without applied bias only shows $s p^{2}(h$-BN) bonded BN bonding, whereas the coating grown with applied bias shows a mixture of $s p^{2}(h-\mathrm{BN})$ and $s p^{3}(c$-BN and $w$-BN) bonded BN.

Table 1. Complete peak assignment for the (FTIR) spectral analysis of the boron nitride coatings.

\begin{tabular}{ccc}
\hline Transmittance Frequency $\mathbf{( \mathbf { c m } ^ { - 1 } )}$ & Peak Assignment & References \\
\hline 786 & $\begin{array}{c}\text { Out-of-plane (B-N-B) bending } \\
\text { modes of } h \text {-BN }\end{array}$ & {$[35,36]$} \\
\hline 1045 & Restrahlen band of $c$-BN & {$[37,38]$} \\
\hline 1224 & $\begin{array}{c}\text { Transverse Optical (TO) mode of } \\
w \text {-BN }\end{array}$ & {$[41]$} \\
\hline 1307 & $\begin{array}{c}\text { In-plane (B-N) stretching modes of } \\
h \text {-BN }\end{array}$ & {$[35,36]$} \\
\hline
\end{tabular}

Using the above equation, we can calculate the relative content of $w$-BN of biasenhanced $\mathrm{BN}$ coating. The estimated volume fraction of $w-\mathrm{BN}$ is $72 \%$ in the bias-enhanced $\mathrm{BN}$ coating. Using a similar kind of equation, we can estimate the volume fraction of $c$-BN and $h-\mathrm{BN}$; the respective volume fractions of $\mathrm{BN}$ of $c-\mathrm{BN}$ and $h-\mathrm{BN}$ are $15 \%$ and $13 \%$.

\subsection{X-ray Photoelectron Spectroscopy}

X-ray photoelectron spectroscopy was carried out to determine the elemental compositions and chemical bonding of the boron nitride $(\mathrm{BN})$ coatings. Figure $2 \mathrm{a}, \mathrm{b}$ shows the high-res x-ray photoelectron spectra of B1s and N1s for BN coatings grown without applied bias. The binding energy peak positions for the hi-res B1s and N1s reveal fits to only $s p^{2}$ bonded BN (ca. $189.7 \mathrm{eV}$ and $397.2 \mathrm{eV}$, respectively) [42-45]. Figure 2c,d shows high-res $\mathrm{x}$-ray photoelectron spectra of B1s and N1s for BN coatings grown with applied bias. These coatings reveal fits to both $s p^{2}$ and $s p^{3}$ bonded BN with the $s p^{3}$ component ca. $191.8 \mathrm{eV}$ and $399.5 \mathrm{eV}$ for B1s and N1s, respectively [42-45]. From the survey spectra, the surface of the bias-enhanced $\mathrm{BN}$ coating was composed of $49.1 \%$ boron, $44.1 \%$ nitrogen, $4 \%$ carbon, and $2.8 \%$ oxygen (rel. at \%) with no other elements present. The atomic ratio of boron and nitrogen was 1.1 and very close to the chemical stoichiometry of BN. A small amount of surface contamination due to adventitious carbon and oxygen is generally present in samples that have been exposed to air. The high-res B1s scan in Figure 2c shows that 8\% boron is B-B bonded, $62 \%$ is $s p^{2} \mathrm{BN}$ bonded and $30 \%$ is $s p^{3} \mathrm{BN}$ bonded. The high-res N1s scan in Figure $2 \mathrm{~d}$ shows $65 \%$ is $s p^{2} \mathrm{BN}$ bonded and $35 \%$ is $s p^{3} \mathrm{BN}$ bonded. The complete peak assignment is shown in Table 2. 

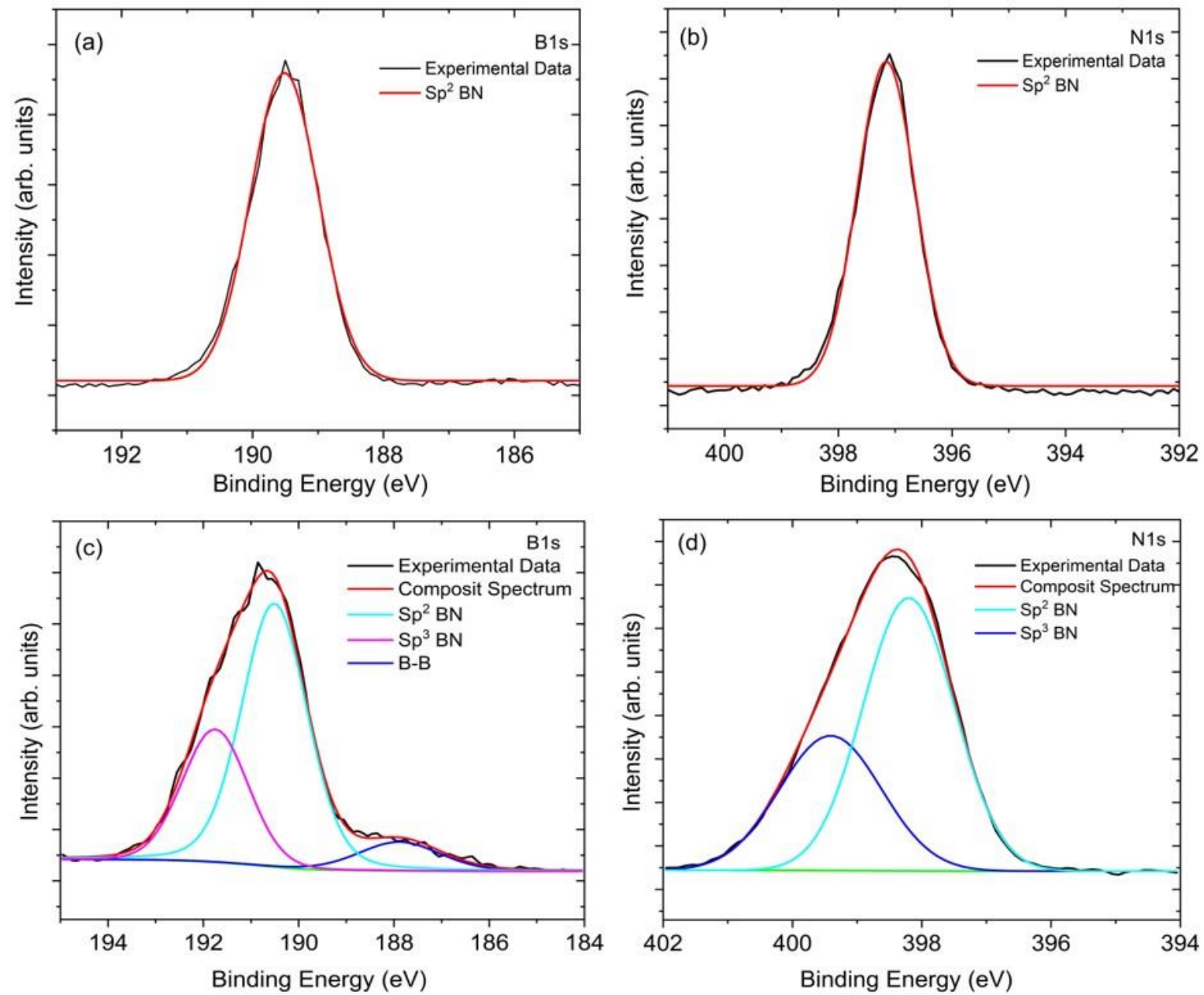

Figure 2. X-ray photoelectron spectra of hi-res (a) B1s and (b) N1s of without external bias BN coating shows only $s p^{2}$ bonded BN. Hi-res (c) B1s and (d) N1s of bias-enhanced BN coating shows both $s p^{2}$ and $s p^{3}$ bonded BN on the spectrum. The detailed compositional analysis with corresponding binding energy is shown in Table 2.

Table 2. XPS compositional analysis and fitted parameters of B1s and N1s.

\begin{tabular}{|c|c|c|c|c|c|}
\hline Sample & Peaks & Binding Energy & Peak Area (\%) & Assignment & References \\
\hline \multirow{2}{*}{$\begin{array}{c}\text { Without Bias } \\
\text { BN }\end{array}$} & B1s & 189.8 & 100 & $s p^{2} \mathrm{BN}$ & {$[44,45]$} \\
\hline & N1s & 397.2 & 100 & $s p^{2} \mathrm{BN}$ & {$[44,45]$} \\
\hline \multirow{5}{*}{$\begin{array}{l}\text { Bias-Enhanced } \\
\text { BN }\end{array}$} & B1s & 188.0 & 8 & B-B & {$[34,46]$} \\
\hline & B1s & 190.5 & 62 & $s p^{2} \mathrm{BN}$ & {$[42,45]$} \\
\hline & B1s & 191.8 & 30 & $s p^{3} \mathrm{BN}$ & {$[42,45]$} \\
\hline & N1s & 398.2 & 65 & $s p^{2} \mathrm{BN}$ & {$[42,45]$} \\
\hline & N1s & 399.5 & 35 & $s p^{3} \mathrm{BN}$ & {$[42,45]$} \\
\hline
\end{tabular}

\subsection{X-ray Diffraction}

The results of the bias-enhanced boron nitride coating using a glancing-angle x-ray diffraction pattern are shown in Figure 3. Two broad diffraction peaks at $2 \theta$ of $24-28^{\circ}$ and $41-45^{\circ}$, along with three other peaks at $52^{\circ}, 55^{\circ}$, and $56^{\circ}$ are present in the diffractogram. Sharp peaks near $52^{\circ}$ and $56^{\circ}$ may be seen on the single crystal Si substrates, which are often influenced by sample orientation during the XRD scan [28]. The peak around $26^{\circ}$ in the XRD pattern is associated with the (002) reflection of $h$-BN. The other weak characteristic 
peak (004) of hexagonal boron nitride around $55^{\circ}$ is also present $[28,47,48]$. The broad peak around $41-45^{\circ}$ is the combination of $s p^{3}$ bonded $w-\mathrm{BN}$ and $c-\mathrm{BN}$. To get better visualization, high resolution XRD was performed at $2 \theta$ of $40-50^{\circ}$. The broad peak at $41-45^{\circ}$ was resolved into two peaks which corresponds to $w$-BN (002) and c-BN (111) [15,42,49-51].

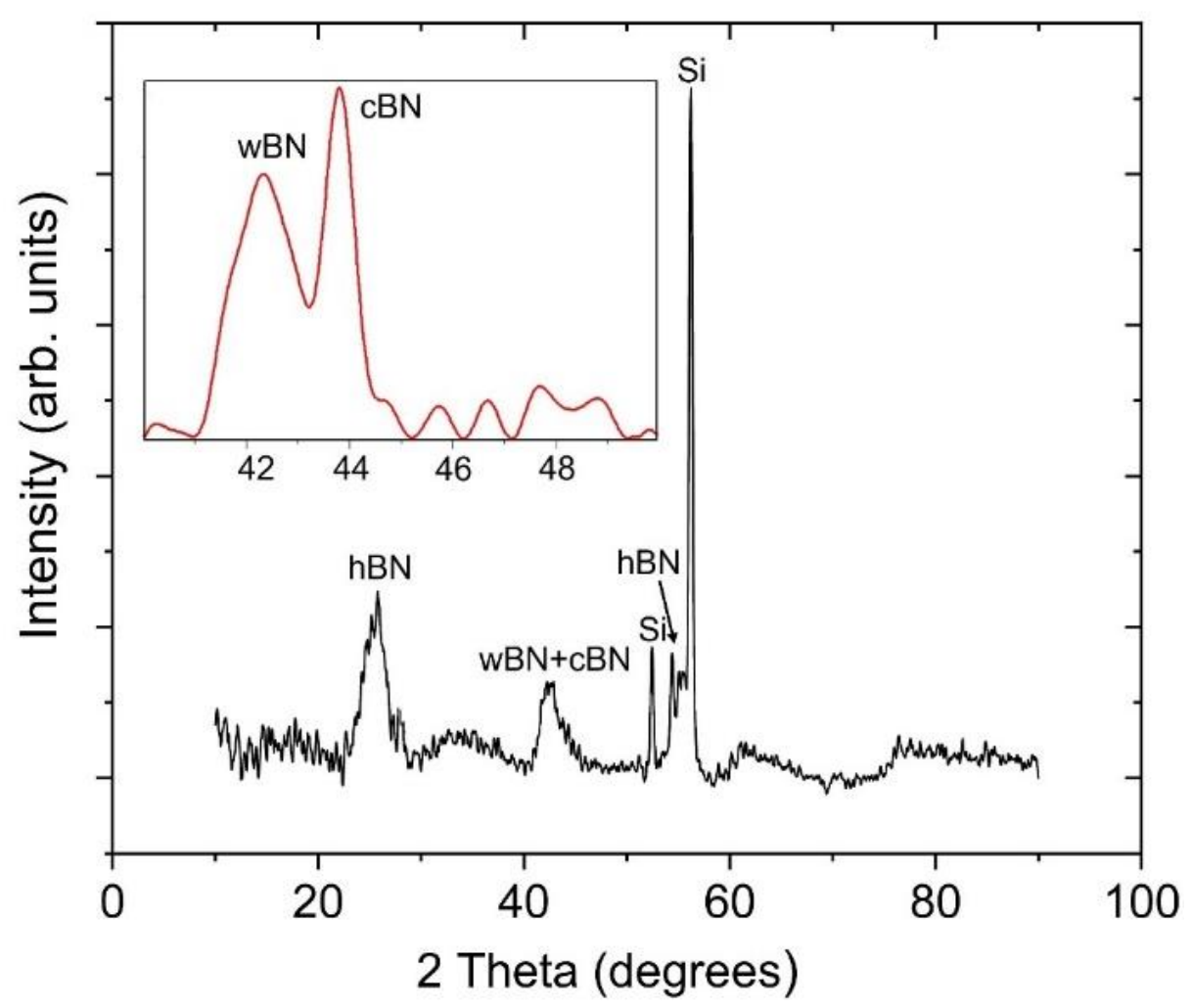

Figure 3. Glancing-angle X-ray diffraction pattern for bias-enhanced boron nitride coating. X-ray diffraction pattern of the coating grown without applied bias is reported in our previous work [28].

\subsection{Nano-Indentation}

Figure 4 shows the nano-indentation hardness data of the boron nitride coatings. The indents were performed to a depth of $600 \mathrm{~nm}$ at several locations $(n=18)$. Figure 4 a shows an average measured hardness of $3.4 \pm 1.7 \mathrm{GPa}$ for the coating grown without applied bias. The load/displacement curve of one representative indent is also shown in Figure $4 \mathrm{~b}$. The relative contribution of elastic and plastic deformation can be calculated from the final unloading depth of the load/displacement curve indicating a high plastic deformation of $67 \%$. Figure $4 \mathrm{c}$ shows an average measured hardness $(n=16)$ of $25.0 \pm 4.3 \mathrm{GPa}$ for the coating grown with applied bias. Figure $4 \mathrm{~d}$ shows the load/displacement curve of the indent with the highest recorded hardness of 31.2 GPa. The final unloading depth of the load/displacement curve can be used to calculate the relative contribution of elastic and plastic deformation. A high elastic recovery of $75 \%$ was found for the boron nitride coating grown with applied bias. Therefore, while the bias-enhanced coating has high elastic recovery, the coating grown without bias shows much higher plastic deformation. 

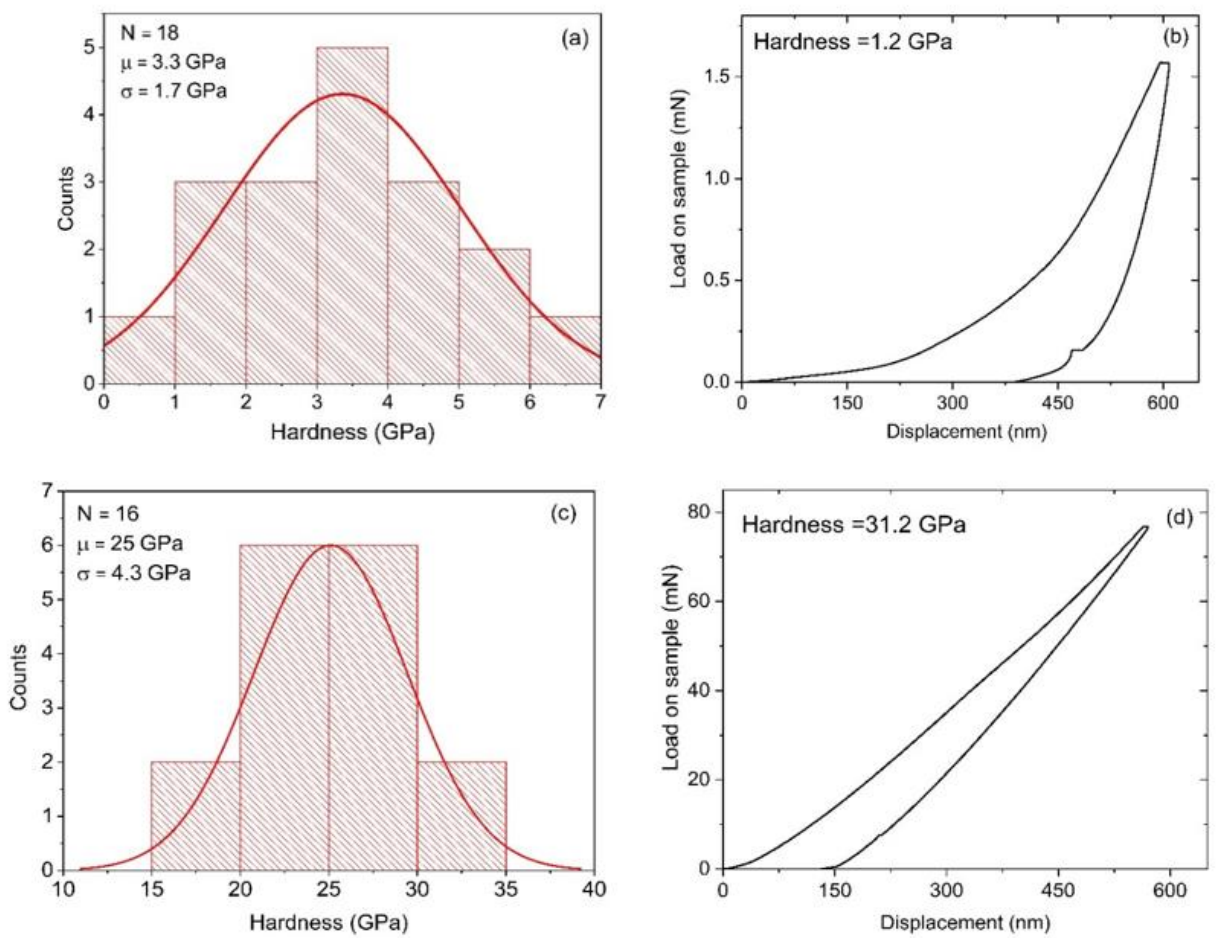

Figure 4. (a) Histogram from 16 indents showing hardness values for without-bias boron nitride coating. (b) Nanoindentation load/displacement curve from one location on the without-bias boron nitride coating at a depth of $600 \mathrm{~nm}$. (c) Histogram from 16 indents showing hardness values for bias-enhanced boron nitride coating. (d) Nanoindentation load/displacement curve from one location on the bias-enhanced boron nitride coating at a depth of $600 \mathrm{~nm}$. The extracted value of nano-indentation hardness $31.2 \mathrm{GPa}$ is also indicated.

\subsection{Scanning Electron Microscopy (SEM)}

The surface morphology of boron nitride coatings was evaluated using scanning electron microscopy, as shown in Figure 5. As reported in our previous study [28], the morphology of hexagonal boron nitride grown without applied bias shows plate-like structures which have been reported for nanocrystalline $h$-BN $[52,53]$. In contrast, the bias-enhanced BN surface shows rounded nodules $\sim 5 \mu \mathrm{m}$ diameter protruding from a very fine-grained base structure.

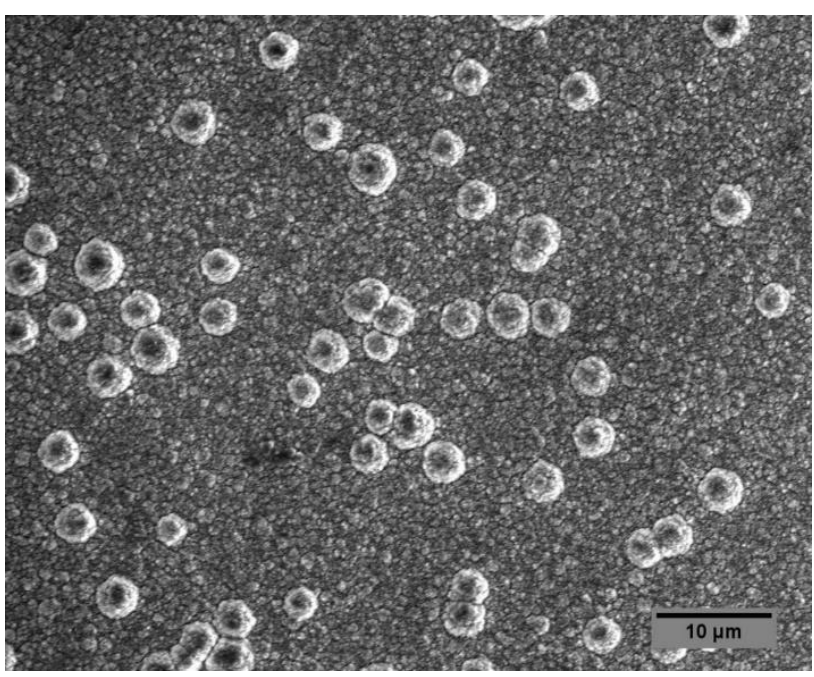

Figure 5. Scanning electron microscopy (SEM) image of bias-enhanced boron nitride coating. Morphology of the coating grown without applied bias is reported in our previous work [28]. 


\section{Discussion}

The challenge of bias-enhanced formation of boron nitride in MPCVD is in finding the range of bias voltage where $s p^{2}$ bonds can transform to $s p^{3}$ bonds. To the best of our knowledge, this work represents the first report of metastable wurtzite BN growth from a low-pressure plasma CVD process. Its formation is facilitated by application of substrate bias. Despite the low expected kinetic barrier for transformation to the more stable hexagonal phase, the wurtzite phase can be quenched and remain stabilized at ambient conditions, albeit in a mixture with hexagonal and cubic forms. According to the XPS and FTIR characterization, the sample prepared without applied bias shows only $s p^{2}$ bonded BN. Application of substrate bias facilitates $s p^{3}$ bonded BN, also confirmed by XPS, $\mathrm{XRD}$ and FTIR analysis. This is supported by the substantial increase in average coating hardness from 3.4 GPa to 25.0 GPa.

Possible mechanisms by which an increase in $s p^{3}$ bonding occurs as well as in the stabilization of the thermodynamically metastable wurtzite $\mathrm{BN}$ phase involve the influence of ion bombardment-induced stress as well as crystalline defect-induced stabilization of the wurtzite phase. The formation of an electric field by applying a negative DC substrate bias directs the transport of positive ions towards the silicon substrate. These ions can impact with considerable kinetic energy to vibrationally excite target $\mathrm{B}$ and $\mathrm{N}$ atoms on the surface, leading to a local rearrangement of atomic positions and bonds. It is expected that the additional ion bombardment raises the atom mobility on the surface and boosts the displacement of the surface atoms. Highly energetic ions can be incorporated into the subsurface region of the substrate and increase compressive stress [32]. Stress is related to the ion energy and ion to atom arrival ratio, which can be described by ion momentum transferred to the coating $[54,55]$. This stress further increases with continued ion bombardment, and the structure densifies, which in turn drives the phase transformation from $h$-BN to $c$ - $\mathrm{BN}$ and $w$-BN. The optimal bias voltage will introduce the stress required to convert soft $s p^{2}$ bonded $\mathrm{BN}$ to the hard $s p^{3}$ bonded cubic and wurtzite structure of BN.

Chen et al. [23] have discovered a stabilization mechanism for $w$-BN (produced utilizing the high pressure/high temperature approach) based on 3D networks of planar defects that are formed by dense network of intersecting stacking faults (ISF) and inversion domain boundaries (IDB). When the two orthogonal planar defects penetrate each other, an ISF-IDB junction is constructed to create a partial dislocation [23,56]. In GaN thin film, the empirical potential calculation model has shown that the ISF-IDB junction has low formation energy [56]. However, the $w$-BN to $h$-BN phase transition involves approximately $\sim 40 \%$ of lattice expansion of along the c axis. The conversion of $h$-BN from $w$-BN requires the movement of the partial dislocations at the ISF-IDB junctions along the $\mathrm{c}$ axis. This is energetically unfavorable and hence the ISF-IDB junctions in $w$-BN will suppress the transformation back to $h$-BN [23]. This mechanism contradicts the generally accepted opinion that crystal defects in materials will necessarily contribute to the initiation of phase transformations. In $h-\mathrm{BN}, \mathrm{N}$, and $\mathrm{B}$ sublattices are embedded together in the same c-plane whereas the two-neighboring c-planes are connected via weak van der Waals interactions. $h$-BN to $w$-BN phase transformation can be generated by applying a high compression stress to $h$-BN along the c-axis such that the $\mathrm{N}$ and $\mathrm{B}$ atoms at adjacent basal planes become close enough for direct chemical bonding. The $\mathrm{N}$ atom from a horizontal plane has an equal opportunity to bond with the upper and lower layer of B atoms. According to Chen et al., if the $\mathrm{N}$ atoms bond with the upper-layer $\mathrm{B}$ atoms on one side and bond with the lower-layer B atoms on the other side, an IDB is formed [23].

In our experiments, DC substrate bias of $-400 \mathrm{~V}$ has converted $s p^{2}$ bonded $\mathrm{BN}$ to hard $s p^{3}$ bonded $c-\mathrm{BN}$ and $w$-BN. We suggest that the ion bombardment created by the substrate bias introduces compressive stress to facilitate $w$-BN formation. Stabilization of $w$-BN may occur via 3D networks of planar defects as described by Chen et al. but direct evidence for this is not yet obtained [23]. Our FTIR spectra bias-enhanced BN coating still shows a very weak hexagonal phase. X-ray photoelectron spectroscopy and X-ray diffraction pattern also shows a mixture of $s p^{2}$ bonded BN and $s p^{3}$ bonded BN. Although the bias-enhanced 
BN coating has both $s p^{2}$ bonded BN and $s p^{3}$ bonded BN, the hardness value of the coating increases by more than a factor of seven. Achieving high hardness with a mixture of $s p^{2}$ and $s p^{3}$ bonded $\mathrm{BN}$ is exciting; planned future experiments will involve varying the bias voltage in an attempt to fully convert $s p^{2}$ to $s p^{3}$ bonded $\mathrm{BN}$. This should further increase the hardness of the coating to the superhard regime ( $>40 \mathrm{GPa}$ ). In order to better understand the mechanism of $s p^{3}$ conversion and wurtzite stabilization, measurement of the coating stress, SEAD pattern by TEM and crystalline defects need to be obtained.

\section{Conclusions}

Boron nitride coatings were deposited in a microwave plasma chemical vapor deposition with and without DC bias applied to the substrate. The applied bias was found to introduce $s p^{3}$ bonded boron nitride in both cubic and wurtzite structures, coexisting with the hexagonal phase. Formation of metastable wurtzite boron nitride using the low temperature plasma method is reported for the first time. This is in contrast to other reports that rely on high temperature-high pressure methods. Based on prior reports, it is expected that compressive stress is induced in the coating due to ion bombardment from substrate biasing. This stress can be responsible for converting $s p^{2}$ to $s p^{3}$ bonded boron nitride, but the observed stabilization of the wurtzite phase needs further study. Although the coating grown using applied bias has a mixture of $s p^{2}$ and $s p^{3}$ bonded BN, the presence of $s p^{3} \mathrm{BN}$ (in cubic and wurtzite forms) is enough to increase average nano-indentation hardness by more than a factor of seven compared to the coating grown without applied bias. Given the outstanding hardness of the wurtzite BN phase, even when compared to diamond, this represents an important finding with implications in achieving superhardness from mixed-phase BN materials.

Author Contributions: Conceptualization, S.A.C.; methodology, K.C.; validation, K.C.; formal analysis, K.C.; investigation, K.C., P.A.B. and V.M.V.; resources, S.A.C.; writing-original draft preparation, K.C.; writing-review and editing, S.A.C.; visualization, K.C., P.A.B. and V.M.V.; supervision, S.A.C.; project administration, S.A.C. All authors have read and agreed to the published version of the manuscript.

Funding: This research was funded by the National Science Foundation (NSF) EPSCoR RII-Track-1 Cooperative Agreement OIA-1655280. This research was supported in part by the Alabama State funded Graduate Research Scholars Program (GRSP). Any opinions, findings, and conclusions or recommendations expressed in this material are those of the authors and do not necessarily reflect the views of the National Science Foundation.

Institutional Review Board Statement: Not applicable.

Informed Consent Statement: Not applicable.

Data Availability Statement: The data presented in this study are available on request from the corresponding author.

Conflicts of Interest: The authors declare no conflict of interest.

\section{References}

1. Hou, X.; Yu, Z.; Chou, K.-C. Facile synthesis of hexagonal boron nitride fibers with uniform morphology. Ceram. Int. 2013, 39, 6427-6431. [CrossRef]

2. Lipp, A.; Schwetz, K.A.; Hunold, K. Hexagonal boron nitride: Fabrication, properties and applications. J. Eur. Ceram. Soc. 1989, 5, 3-9. [CrossRef]

3. Samantaray, C.B.; Singh, R.N. Review of synthesis and properties of cubic boron nitride (c-BN) thin films. Int. Mater. Rev. 2013, 50, 313-344. [CrossRef]

4. Pan, Z.; Sun, H.; Zhang, Y.; Chen, C. Harder than diamond: Superior indentation strength of wurtzite BN and lonsdaleite. Phys. Rev. Lett 2009, 102, 055503. [CrossRef] [PubMed]

5. Mirkarimi, P.B.; Medlin, D.L.; McCarty, K.F.; Dibble, D.C.; Clift, W.M.; Knapp, J.A.; Barbour, J.C. The synthesis, characterization, and mechanical properties of thick, ultrahard cubic boron nitride films deposited by ion-assisted sputtering. J. Appl. Phys. 1997, 82, 1617-1625. [CrossRef] 
6. Zhang, W.J.; Bello, I.; Lifshitz, Y.; Chan, K.M.; Wu, Y.; Chan, C.Y.; Meng, X.M.; Lee, S.T. Thick and adherent cubic boron nitride films grown on diamond interlayers by fluorine-assisted chemical vapor deposition. Appl. Phys. Lett. 2004, 85, $1344-1346$. [CrossRef]

7. Komatsu, T.; Kakudate, Y.; Fujiwara, S. Heat resistance of a shock-synthesized B-C-N heterodiamond. J. Chem. Soc. Faraday Trans. 1996, 92, 5067-5071. [CrossRef]

8. Bello, I.; Chan, C.Y.; Zhang, W.J.; Chong, Y.M.; Leung, K.M.; Lee, S.T.; Lifshitz, Y. Deposition of thick cubic boron nitride films: The route to practical applications. Diam. Relat. Mater. 2005, 14, 1154-1162. [CrossRef]

9. Tasuku Shimizu, T.N.; Shunichi, S. Thin film synthesis of wurtzite boron nitride by femtosecond pulsed laser deposition. In Proceedings of the ROMOPTO 2006: Eighth Conference on Optics, 2006, Sibiu, Romania, 1 August 2007.

10. Miyata, N.; Moriki, K.; Mishima, O.; Fujisawa, M.; Hattori, T. Optical constants of cubic boron nitride. Phys. Rev. B Condens. Matter 1989, 40, 12028-12029. [CrossRef] [PubMed]

11. Nose, K.; Oba, H.; Yoshida, T. Electric conductivity of boron nitride thin films enhanced by in situ doping of zinc. Appl. Phys. Lett. 2006, 89, 112124. [CrossRef]

12. Yin, H.; Pongrac, I.; Ziemann, P. Electronic transport in heavily Si doped cubic boron nitride films epitaxially grown on diamond(001). J. Appl. Phys. 2008, 104, 023703. [CrossRef]

13. Kojima, K.; Nose, K.; Kambara, M.; Yoshida, T. Effects of magnesium doping on growth and electric conductivity of nanocrystalline cubic boron nitride thin films. J. Phys. D Appl. Phys. 2009, 42, 055304. [CrossRef]

14. Wenjun Zhang, Y.M.C.; Bin He, I.; Bello, S.-T.L. Cubic Boron Nitride Films: Properties and Applications. Compr. Hard Mater. 2014, 3, 33. [CrossRef]

15. Yang, J.H.C.; Teii, K.; Chang, C.C.; Matsumoto, S.; Rafailovich, M. Biocompatible Cubic Boron Nitride: A Noncytotoxic Ultrahard Material. Adv. Funct. Mater. 2020, 31, 2005066. [CrossRef]

16. Sajjad, M.; Morell, G.; Feng, P. Advance in novel boron nitride nanosheets to nanoelectronic device applications. ACS Appl. Mater. Interfaces 2013, 5, 5051-5056. [CrossRef]

17. Konyashin, I.; Bill, J.; Aldinger, F. Plasma-assisted CVD of cubic boron nitride. Chem. Vap. Depos. 1997, 3, 239-255. [CrossRef]

18. Saitoh, H.; Yarbrough, W.A. Preparation and characterization of nanocrystalline cubic boron nitride by microwave plasmaenhanced chemical vapor deposition. Appl. Phys. Lett. 1991, 58, 2228-2230. [CrossRef]

19. Saitoh, H.; Yarbrough, W.A. Growth of cubic boron nitride on diamond particles by microwave plasma enhanced chemical vapor deposition. Appl. Phys. Lett. 1991, 58, 2482-2484. [CrossRef]

20. Chong, Y.M.; Ma, K.L.; Leung, K.M.; Chan, C.Y.; Ye, Q.; Bello, I.; Zhang, W.; Lee, S.T. Synthesis and Mechanical Properties of Cubic Boron Nitride /Nanodiamond Composite Films. Chem. Vap. Depos. 2006, 12, 33-38. [CrossRef]

21. Monteiro, S.N.; Skury, A.L.D.; de Azevedo, M.G.; Bobrovnitchii, G.S. Cubic boron nitride competing with diamond as a superhard engineering material-An overview. J. Mater. Res. Technol. 2013, 2, 68-74. [CrossRef]

22. Kurakevych, O.O.; Solozhenko, V.L. High-Pressure Design of Advanced BN-Based Materials. Molecules 2016, 21, 1399. [CrossRef]

23. Chen, C.; Yin, D.; Kato, T.; Taniguchi, T.; Watanabe, K.; Ma, X.; Ye, H.; Ikuhara, Y. Stabilizing the metastable superhard material wurtzite boron nitride by three-dimensional networks of planar defects. Proc. Natl. Acad. Sci. USA 2019, 116, 11181-11186. [CrossRef]

24. Singh, R.; Kalita, G.; Mahyavanshi, R.D.; Adhikari, S.; Uchida, H.; Tanemura, M.; Umeno, M.; Kawahara, T. Low temperature wafer-scale synthesis of hexagonal boron nitride by microwave assisted surface wave plasma chemical vapour deposition. AIP Adv. 2019, 9, 035043. [CrossRef]

25. Nocua, J.E.; Morell, G. Straightforward Deposition of Uniform Boron Nitride Coatings by Chemical Vapor Deposition. MRS Adv. 2018, 3, 191-197. [CrossRef]

26. Hidalgo, A.; Makarov, V.; Morell, G.; Weiner, B.R. High-Yield Synthesis of Cubic and Hexagonal Boron Nitride Nanoparticles by Laser Chemical Vapor Decomposition of Borazine. Dataset Pap. Nanotechnol. 2013, 2013, 1-5. [CrossRef]

27. Deura, M.; Kutsukake, K.; Ohno, Y.; Yonenaga, I.; Taniguchi, T. Nanoindentation measurements of a highly oriented wurtzite-type boron nitride bulk crystal. Jpn. J. Appl. Phys. 2017, 56, 030301. [CrossRef]

28. Chakrabarty, K.; Arnold, I.; Catledge, S.A. Hexagonal boron nitride grown using high atomic boron emission during microwave plasma chemical vapor deposition. J. Vac. Sci. Technol. A 2019, 37, 061507. [CrossRef]

29. Onodera, A.; Miyazaki, H.; Fujimoto, N. Phase transformation of wurtzite-type boron nitride at high pressures and temperatures. J. Chem. Phys. 1981, 74, 5814-5816. [CrossRef]

30. Singh, B.P. Characterization of wurtzitic boron nitride compacts. J. Mater. Sci. 1987, 22, 495-498. [CrossRef]

31. Onodera, A.; Inoue, K.; Yoshihara, H.; Nakae, H.; Matsuda, T.; Hirai, T. Synthesis of cubic boron nitride from rhombohedral form under high static pressure. J. Mater. Sci. 1990, 25, 4279-4284. [CrossRef]

32. Shtansky, D.V.; Yamada-Takamura, Y.; Yoshida, T.; Ikuhara, Y. Mechanism of nucleation and growth of cubic boron nitride thin films. Sci. Technol. Adv. Mater. 2001, 1, 219-225. [CrossRef]

33. Ramkorun, B.; Chakrabarty, K.; Catledge, S.A. Effects of direct current bias on nucleation density of superhard boron-rich boron carbide films made by microwave plasma chemical vapor deposition. Mater. Res. Express 2021, 8, 046401. [CrossRef]

34. Chakrabarty, K.; Chen, W.C.; Baker, P.A.; Vijayan, V.M.; Chen, C.C.; Catledge, S.A. Superhard Boron-Rich Boron Carbide with Controlled Degree of Crystallinity. Materials 2020, 13, 3622. [CrossRef] 
35. Ulrich, S.; Scherer, J.; Schwan, J.; Barzen, I.; Jung, K.; Scheib, M.; Ehrhardt, H. Preparation of cubic boron nitride films by radio frequency magnetron sputtering and radio frequency ion plating. Appl. Phys. Lett. 1996, 68, 909-911. [CrossRef]

36. Matsuoka, M.; Langhi Jr., M.P.; Isotani, S.; Chubaci, J.F.D. Fourier transform infrared spectroscopy analysis of thin boron nitride films prepared by ion beam assisted deposition. Phys. Status Solidi C 2014, 11, 509-512. [CrossRef]

37. Zhou, Y.L.; Zhi, J.F.; Wang, P.F.; Chong, Y.M.; Zou, Y.S.; Zhang, W.J.; Lee, S.T. Surface functionalization of cubic boron nitride films for biological sensing applications. Appl. Phys. Lett. 2008, 92, 163105. [CrossRef]

38. Hu, C.; Kotake, S.; Suzuki, Y.; Senoo, M. Boron nitride thin films synthesized by reactive sputtering. Vacuum 2000, 59, 748-754. [CrossRef]

39. Kuhr, M.; Reinke, S.; Kulisch, W. Nucleation of cubic boron nitride (c-BN) with ion-induced plasma-enhanced CVD. Diam. Relat. Mater. 1995, 4, 375-380. [CrossRef]

40. Zhao, Y.; Gao, W.; Xu, B.; Li, Y.-A.; Li, H.-D.; Gu, G.-R.; Yin, H. Thick c-BN films deposited by radio frequency magnetron sputtering in argon/nitrogen gas mixture with additional hydrogen gas. Chin. Phys. B 2016, 25, 106801. [CrossRef]

41. Lili Yu, B.G.; Zhil, C.; Chuantao, S.; Deliang, C.; Chengjian, W.; Qilong, W.; Minhua, J. In situ FTIR investigation on phase transformations in BN nanoparticles. Chin. Sci. Bull. 2005, 50, 2827-2831. [CrossRef]

42. Lian, G.; Zhang, X.; Tan, M.; Zhang, S.; Cui, D.; Wang, Q. Low-temperature solid state synthesis and in situ phase transformation to prepare nearly pure cBN. Dalton Trans. 2011, 40, 6961-6967. [CrossRef] [PubMed]

43. Park, K.S.; Lee, D.Y.; Kim, K.J.; Moon, D.W. Observation of a hexagonal BN surface layer on the cubic BN film grown by dual ion beam sputter deposition. Appl. Phys. Lett. 1997, 70, 315-317. [CrossRef]

44. Jiang, L.; Fitzgerald, A.G.; Rose, M.J.; Lousa, A.; Gimeno, S. Formation of cubic boron nitride films by r.f. magnetron sputtering. Surf. Interface Anal. 2002, 34, 732-734. [CrossRef]

45. Angleraud, B.; Cahoreau, M.; Jauberteau, I.; Aubreton, J.; Catherinot, A. Nitrogen ion beam-assisted pulsed laser deposition of boron nitride films. J. Appl. Phys. 1998, 83, 3398-3403. [CrossRef]

46. Moulder, J.F. Handbook of X-ray Photoelectron Spectroscopy: A Reference Book of Standard Spectra for Identification and Interpretation of XPS Data; Physical Electronics Division; Perkin-Elmer Corporation: Eden Prairie, MN, USA, 1992; p. 261.

47. Ji, C.; Levitas, V.I.; Zhu, H.; Chaudhuri, J.; Marathe, A.; Ma, Y. Shear-induced phase transition of nanocrystalline hexagonal boron nitride to wurtzitic structure at room temperature and lower pressure. Proc. Natl. Acad. Sci. USA 2012, 109, 19108-19112. [CrossRef]

48. Yuan, S.; Journet, C.; Linas, S.; Garnier, V.; Steyer, P.; Benayoun, S.; Brioude, A.; Toury, B. How to Increase the h-BN Crystallinity of Microfilms and Self-Standing Nanosheets: A Review of the Different Strategies Using the PDCs Route. Crystals 2016, 6, 55. [CrossRef]

49. Luo, K.; Zhang, Y.; Yu, D.; Li, B.; Hu, W.; Liu, Y.; Gao, Y.; Wen, B.; Nie, A.; Zhao, Z.; et al. Small onion-like BN leads to ultrafine-twinned cubic BN. Sci. China Mater. 2019, 62, 1169-1176. [CrossRef]

50. Liu, Y.; Zhan, G.D.; Wang, Q.; He, D.; Zhang, J.; Liang, A.; Moellendick, T.E.; Zhao, L.; Li, X. Hardness of Polycrystalline Wurtzite Boron Nitride (wBN) Compacts. Sci. Rep. 2019, 9, 10215. [CrossRef]

51. Sōma, T.; Sawaoka, A.; Saito, S. Characterization of wurtzite type boron nitride synthesized by shock compression. Mater. Res. Bull. 1974, 9, 755-762. [CrossRef]

52. Matović, B.; Luković, J.; Nikolić, M.; Babić, B.; Stanković, N.; Jokić, B.; Jelenković, B. Synthesis and characterization of nanocrystaline hexagonal boron nitride powders: XRD and luminescence properties. Ceram. Int. 2016, 42, 16655-16658. [CrossRef]

53. Rehman, M.M.; Siddiqui, G.U.; Kim, S.; Choi, K.H. Resistive switching effect in the planar structure of all-printed, flexible and rewritable memory device based on advanced 2D nanocomposite of graphene quantum dots and white graphene flakes. J. Phys. D Appl. Phys. 2017, 50, 335104. [CrossRef]

54. Klett, A.; Freudenstein, R.; Plass, M.F.; Kulisch, W. Stress of c-BN thin films: A parameter investigation. Surf. Coat. Technol. 1999, 116-119, 86-92. [CrossRef]

55. Zeitler, M.; Sienz, S.; Rauschenbach, B. Study of stress evolution of boron nitride films prepared by ion assisted deposition. J. Vac. Sci. Technol. A Vac. Surf. Film. 1999, 17, 597-602. [CrossRef]

56. Kioseoglou, J.; Dimitrakopulos, G.P.; Komninou, P.; Polatoglou, H.M.; Serra, A.; Béré, A.; Nouet, G.; Karakostas, T. Junction lines of inversion domain boundaries with stacking faults in GaN. Phys. Rev. B 2004, 70, 115331. [CrossRef] 